\title{
LEVANTAMENTO DE BRIÓFITAS E PTERIDÓFITAS EM MATA CILIAR NO CENTRO URBANO DE CAÇADOR-SC
}

Survey of Bryophytes and Pteridophytes in Ciliriary Woods in the Urban

Center in Caçador-SC

\author{
Alex Guilherme Lopes Scotti ${ }^{1}$ \\ Maria Fabíola Ribeiro dos Santos ${ }^{2}$ \\ Marizete Müller ${ }^{3}$ \\ Debora Ceretta Jung ${ }^{4}$ \\ Recebido em: 11 out. 2012 \\ Aceito em: 26 abr. 2013
}

\section{RESUMO}

Briófitas e Pteridófitas são plantas pioneiras na recuperação vegetal de áreas degradadas, apesar de sua grande importância para os ambientes onde vivem, são muitas vezes ignoradas ou despercebidas pela maioria das pessoas. A falta de dados sobre esses grupos vegetais instigou uma pesquisa referente a briófitas e pteridófitas na região de caçador - SC. O objetivo principal foi a criação de um banco de dados com os espécimes encontrados, que foram posteriormente descritos em um Herbário Virtual, disponibilizado na página da Universidade Alto Vale do Rio do Peixe UNIARP, dentro do Curso de Ciências Biológicas com o seguinte link: http://extranet.uniarp.edu.br/biologicas/herbario/default.aspx. Durante a execução da pesquisa e da realização da mesma foram coletadas amostras na margem do Rio do Peixe, na região central do município de Caçador. As amostras foram conservadas em laboratório, possibilitando fotografar os detalhes e analisar ao microscópio e microscópio estereoscópico. Com os dados das amostras colhidos, realizou-se 0

\footnotetext{
${ }^{1}$ Graduando em Ciências Biológicas pela Universidade Alto Vale do Rio do Peixe - Caçador/SC. e-mail: muller05@hotmail.com.

${ }^{2}$ Graduando em Ciências Biológicas pela Universidade Alto Vale do Rio do Peixe - Caçador/SC. e-mail: alexscotti_18m@hotmail.com.

${ }^{3}$ Graduando em Ciências Biológicas pela Universidade Alto Vale do Rio do Peixe - Caçador/SC. e-mail: mariafabiola1992@hotmail.com.

4 Bióloga, Pós-graduada em Biologia Econômica pela Universidade do Contestado e docente da Universidade Alto Vale do Rio do Peixe, Campus Caçador - e-mail: deborajung@uniarp.edu.br.
} 
levantamento bibliográfico para efetuar a catalogação das plantas encontradas. Foram registrados e catalogados cinco gêneros de pteridófitas, Polypodium, Cyathea, Adiantum Pteridium e Selaginella e um gênero de briófita, Polytrichum.

Palavras - chave: briófitas, pteridófitas, herbário virtual.

\section{ABSTRACT}

Bryophytes and Pteridophytes are pioneer plants in vegetable recovery of degraded areas, despite its great importance to the environments where they live; they are often ignored or overlooked by most people. The lack of data on these plant groups instigated a search related to bryophytes and Pteridophytes in the region of Caçador-SC. The main objective was to create a database with the specimens found which were later described in a Virtual Herbarium, it is available in the website of Alto Vale do Rio do Peixe University - UNIARP, within the course of Biological Sciences with the following link:http://extranet.uniarp.edu.br/biologicas/herbario/default.aspx. During the execution and the realization of the research, samples were collected on the bank of the Rio do Peixe, in the central region in the city of Caçador. The samples were stored in the laboratory, enabling photographing the details and examine under the microscope and stereomicroscope. With data collected samples, it was hold the bibliographical survey to cataloging the plants found. Five genera of pteridophytes were recorded and cataloged, Polypodium, Cyathea, Adiantum Pteridium e Selaginella and one genus of bryophytes, Polytrichum.

Keywords: Bryophytes, Pteridophytes, Virtual Herbarium

\section{INTRODUÇÃO}

As briófitas são as plantas mais primitivas, avasculares, de pequeno porte e que dependem exclusivamente de água para o seu processo reprodutivo, habitando desta maneira ambientes preferencialmente úmidos.

As pteridófitas foram as plantas sucessoras das briófitas no decorrer da evolução, possuem um grande destaque na flora terrestre, podendo ser de pequeno ou grande porte. 
Encontramos uma grande carência de dados referentes ao estudo de briófitas e pteridófitas na região meio oeste de Santa Catarina, por isso vê-se a necessidade de criar fontes informativas, para que nossa região possa ter registros de sua flora de microambientes situados as margens do Rio do Peixe.

O presente trabalho teve por objetivo a realização do levantamento de briófitas e pteridófitas encontradas em área de mata ciliar bastante degradada na região urbana central do município de Caçador/SC, no período de Junho de 2011 a julho de 2012; e a criação de um banco de dados, baseados em imagens fotográficas dos espécimes encontrados. Com o desenvolver da atividade foi possível um espaço físico e condições próprias para a confecção e armazenamento de exsicatas.

O levantamento foi feito por meio de coletas periódicas de espécimes, identificação taxonômica e descrição dos gêneros de briófitas e pteridófitas encontradas na área em estudo, além de confecção de exsicatas de pteridófitas e imagens fotográficas.

O banco de dados que constitui o Herbário Virtual é uma ferramenta de apoio à pesquisa na área da botânica, inicialmente com briófitas e pteridófitas na região de Caçador-SC, com ampliação prevista para os demais grupos vegetais, gimnospermas e angiospermas.

\section{MATERIAIS E MÉTODOS}

Área de estudo

A área selecionada foi de aproximadamente $4235 \mathrm{~m}^{2}$, sendo 7 metros de largura e 605 metros de comprimento, de mata ciliar do Rio do 
Peixe, na região central urbana do município de Caçador, no meio oeste do estado de Santa Catarina entre as pontes Selso A. Veronese e Pedro Bortolon. A área em estudo sofre constante intervenção humana, sendo bastante degradada e possuindo terreno irregular, em grande parte, devido a erosões no solo. A área foi visitada a cada vinte dias, por um período de um ano, para a coleta de espécimes de briófitas e pteridófitas.

Coleta de espécimes de briófitas e pteridófitas

Foram coletadas amostras de briófitas e pteridófitas contendo sempre que possível, a planta com raízes, caule e folhas. A coleta foi feita por meio do uso de estilete, espátula e pinça. As amostras foram fotografadas no local da coleta, transportadas em bandejas plásticas até 0 laboratório, onde ficavam armazenadas e refrigeradas $\left( \pm 6^{\circ} \mathrm{C}\right)$ para que posteriormente pudessem ser feitas análises laboratoriais. Para as análises foram utilizados microscópio estereoscópico e microscópio óptico, visando caracterizar e identificar os gêneros, bem como a realização de registros fotográficos laboratoriais.

A identificação dos gêneros de pteridófitas e briófitas se deu por meio da análise das características morfológicas com o auxílio de lupa estereoscópica, microscópio óptico e da literatura vigente.

Foram realizados diversos registros fotográficos a campo e laboratoriais a fim de obter material para a catalogação e para o preenchimento do banco de dados do Herbário Virtual.

Com os gêneros de pteridófitas identificados foram feitas exsicatas a fim de que os espécimes catalogados fiquem arquivados e possam ser consultados posteriormente.

Durante a realização deste trabalho de pesquisa e criação de um 
Herbário Virtual, as professoras coordenadoras estiveram visitando o Herbário da Universidade Federal de Santa Catarina (UFSC), a fim de se iniciar um trabalho dentro das regras utilizadas na organização de um Herbário.

Dados geográficos e climáticos

Caçador situa-se entre os paralelos $26^{\circ}$ e $27^{\circ}$ e os meridianos $50^{\circ}$ e $52^{\circ}$ oeste, o solo é do tipo terra-roxa devido a decomposição das rochas basálticas; está a uma altitude média de 1.000 metros acima do nível do mar, possuindo topografia acidentada intercalada por morros, colinas, vales e chapadas. O clima é caracterizado por inverno frio e seco e verão quente e úmido, sendo a temperatura média anual de $16,6{ }^{\circ} \mathrm{C}$ (PREFEITURA MUNICIPAL DE CAÇADOR, 2012).

\section{RESULTADOS E DISCUSSÃO}

As briófitas desempenham um papel importante em muitos ecossistemas, visto que auxilia no armazenamento de água; na captação dos nutrientes da chuva e nas interações ecológicas ao servir de habitat para animais. Também são excelentes indicadores das mudanças climáticas, pois geralmente reagem a essas mudanças .

As briófitas podem ocorrer em diferentes microambientes com condições muito variáveis, como, por exemplo, base dos troncos, fissuras, ramos, tronco, calçadas, muros, entre muitos outros. Visto que as condições são diferentes de acordo com a altura e a posição na árvore, quanto à disponibilidade de nutrientes, iluminação e umidade, estas influenciam diretamente na colonização (COSTA, 2010). 
As briófitas coletadas e classificadas apresentavam visivelmente baixa qualidade de gametófito, sendo que nas épocas de maior incidência de chuvas elas praticamente desapareceram.

Com o levantamento de briófitas foi possível a identificação do gênero Polytrichum, pertencente à família Pilotrichaceae. As amostras coletadas foram retiradas de paredes rochosas debaixo da ponte Pedro Bortolon.

O gênero Polytrichum pertence à ordem Bryales, que compreende musgos que habitam rochas, solos e troncos de árvores. Em Polytrichum (Figura 1) o gametófito transporta o esporófito e a cápsula, que é coberta pela caliptra. O gametófito se encontra diferenciado em caulóide e filídios. E no interior da cápsula, imediatamente abaixo da região do opérculo, diferenciam-se fileiras verticais de células que, mais tarde, constituem os dentes do peristômio (JOLY, 2002).

Figura 1: Gênero Polytrichum. A) Usando como habitat uma rocha; B) Visto ao microscópio estereoscópico; C) Cápsula com os dentes de peristômio em evidência; D) Partes de um esporófito: a) caliptra, b) cápsula e c) seta.

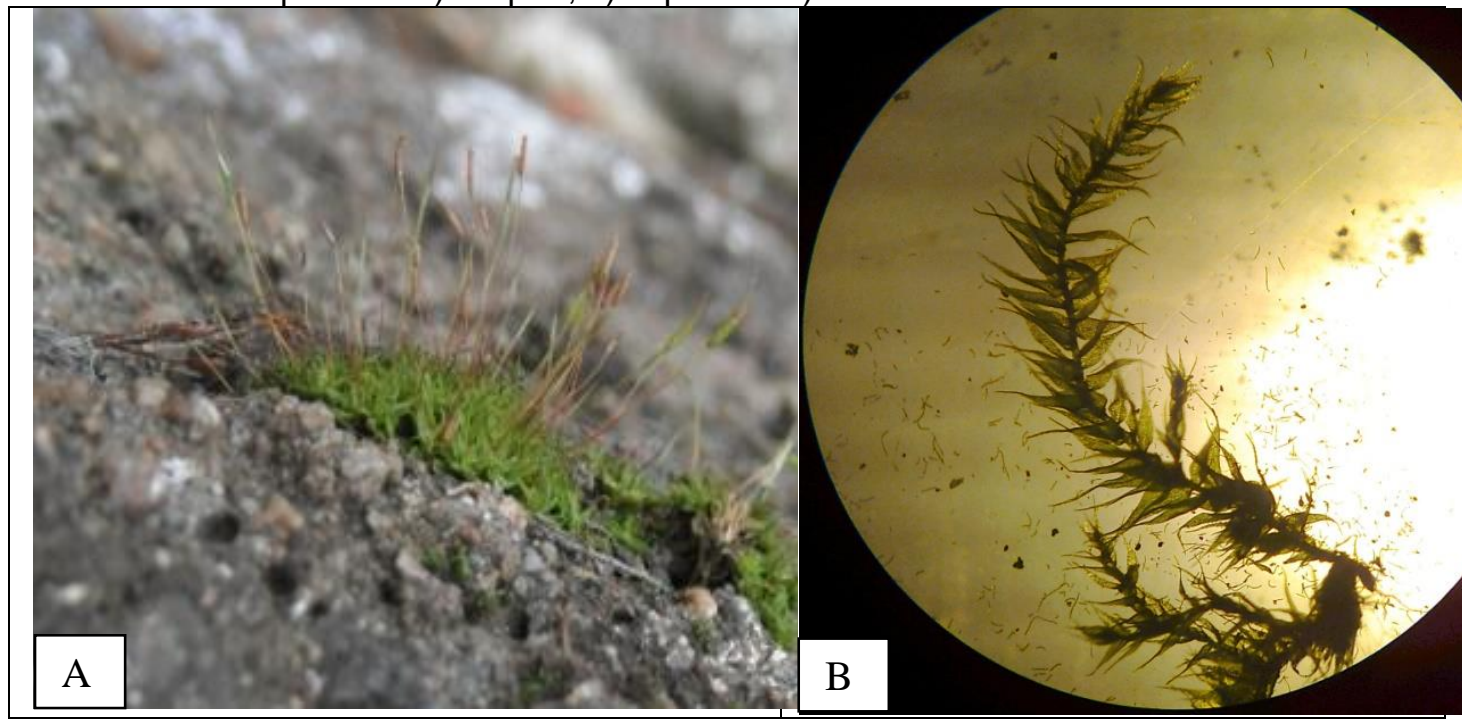




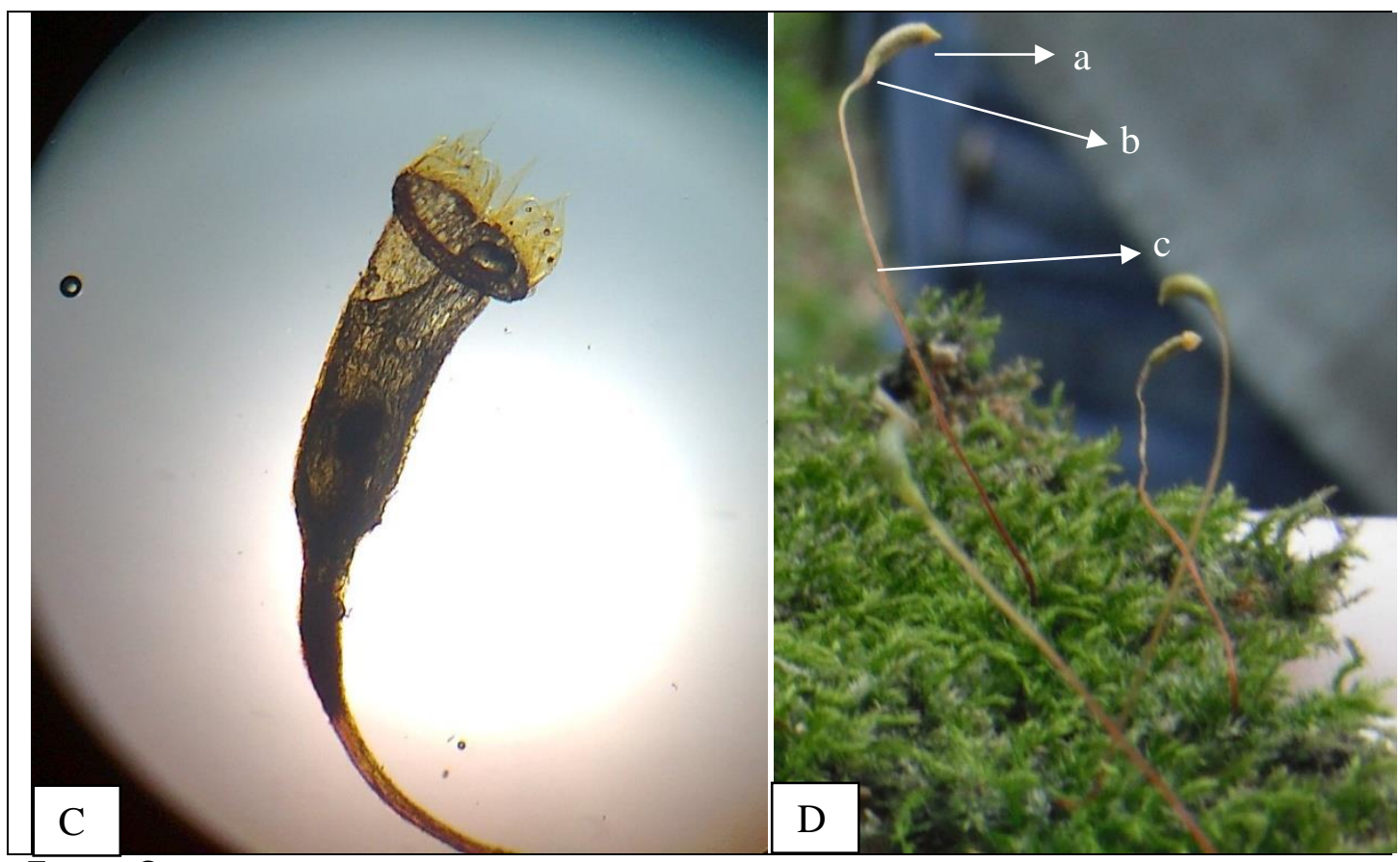

Fonte: Os autores.

As pteridófitas são responsáveis por iniciar o processo de sucessão ecológica no tocante a plantas vasculares. Uma vez que o ambiente precisa ser repovoado seguirá uma ordem evolutiva, dando ao espaço em recuperação tempo hábil para que ele possa tornar-se novamente equilibrado.

O levantamento de pteridófitas resultou na identificação de duas ordens, três famílias e cinco gêneros diferentes (Tabela 1). Representantes da ordem Filicales foram os mais encontrados, se destacando duas famílias: Polypodiaceae, com três gêneros, Polypodium, Adiantum e Pteridium; e Cyatheaceae com apenas o gênero Cyathea. A ordem Selaginellales representada pela família Selaginellaceae e pelo gênero Selaginella. 
Tabela 1. Lista dos gêneros de pteridófitas ocorrentes no centro urbano de Caçador/SC de junho de 2011 a junho de 2012.

\begin{tabular}{lll}
\hline Ordens & Famílias & Gêneros \\
\hline Filicales & Polypodiaceae & Polypodium \\
& & Adiantum \\
& & Pteridium \\
& Cyatheaceae & Cyathea \\
Selaginellales & Selaginellaceae & Selaginella \\
\hline
\end{tabular}

Fonte: Os autores.

FAMILIA POLYPODIACEAE

GÊNERO ADIANTUM

O gênero Adiantum compreende plantas denominadas popularmente como avencas. São caracterizadas por apresentar 0 esporófito com folhas longo-pecíoladas, lâmina repartida em muitos segmentos que, geralmente, são semelhantes e de cor verde-azulada na porção inferior (PIQUÉ e BRITO, 1996). O pecíolo se apresenta na maioria das espécies, de cor marrom-escuro ou preta (PIQUÉ e BRITO, 1996).

De acordo com Joly (1998), o soro do gênero Adiantum não está protegido por indúsio e sim pela margem recurvada do folíolo. Pode-se dizer então que há a presença de um 'falso indúsio' (PIQUÉ e BRITO, 1996).

As plantas do gênero se reproduzem através de esporângios ou, de maneira mais fácil, por divisão da touceira (PIQUÉ e BRITO, 1996). As avencas coletadas em sua maioria estavam em regiões íngremes, muito próximas do rio, estando sempre em touceiras grandes, as quais evidentemente puderam ser divididas para aumentar a chances de reprodução. As avencas foram nossas últimas amostras coletadas, tinham 
acabado de desenvolver-se após um período crítico, onde o barranco havia sido varrido por enchentes e posteriormente modificado pela ação de limpeza dos órgãos competentes.

Figura 2: Gênero Adiantum. A) e B) Usando como habitat o barranco da margem do Rio do Peixe; C) Ramo, com destaque para as folhas com lâminas repartidas em muitos segmentos; de cor verde-azulada na porção inferior; D) Soro pela margem recurvada do folíolo.
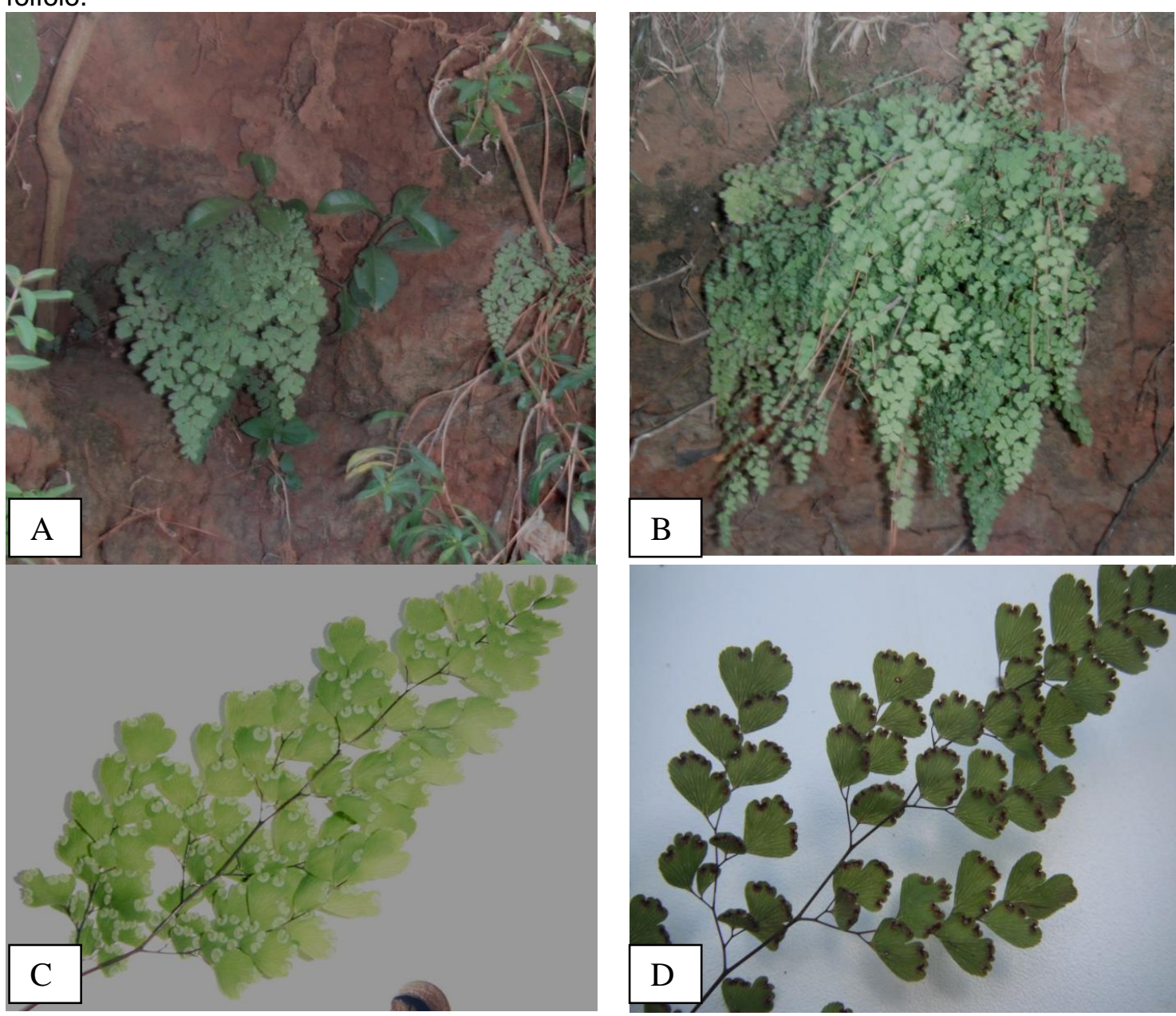

Fonte: Os autores.

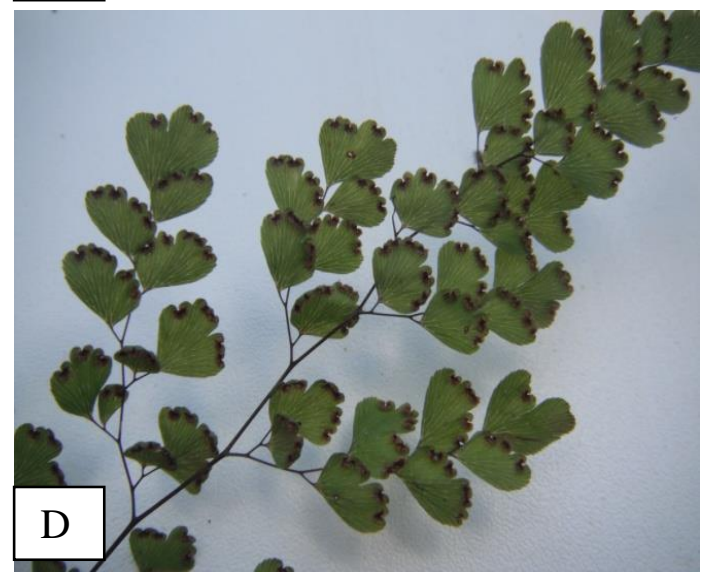

Ignis | Caçador | v.2 | n.1 | p. 6-22 | jan./jun. 2013 
FAMÍLIA POLYPODIACEAE

\section{GÊNERO POLYPODIUM}

O gênero Polypodium pertence à classe filices, que reúne os vegetais que formam numerosos esporângios na face dorsal das folhas (BUCKUP). E à família Polypodiaceae, que têm a característica dos esporângios de um mesmo soro, maturarem em períodos distintos, sendo o soro considerado misto (JOLY, 2002) e a única família a possuir este tipo de soro (SMITH, 1955). Em Polypodium o soro se encontra nu, pois não está protegido por indúsio (JOLY, 2002).

O gênero Polypodium foi encontrado sobre o xaxim.

Figura 3: Gênero Polypodium; A) Folhas de um mesmo ramo com períodos de maturação de esporângio diferentes; B) Usando como substrato o xaxim; C) Soro (conjunto de esporângios) ainda sem maturar; D) Soro maturo.

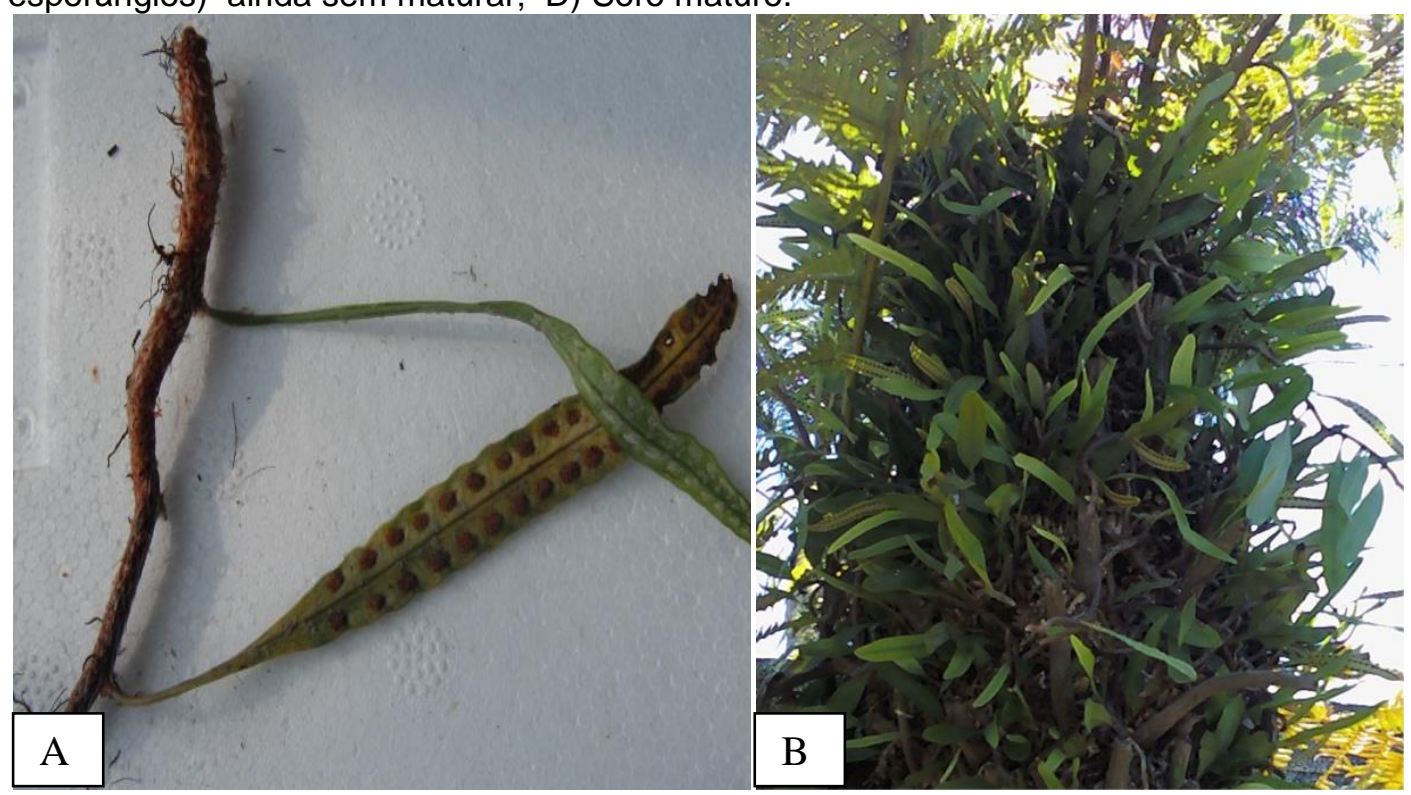




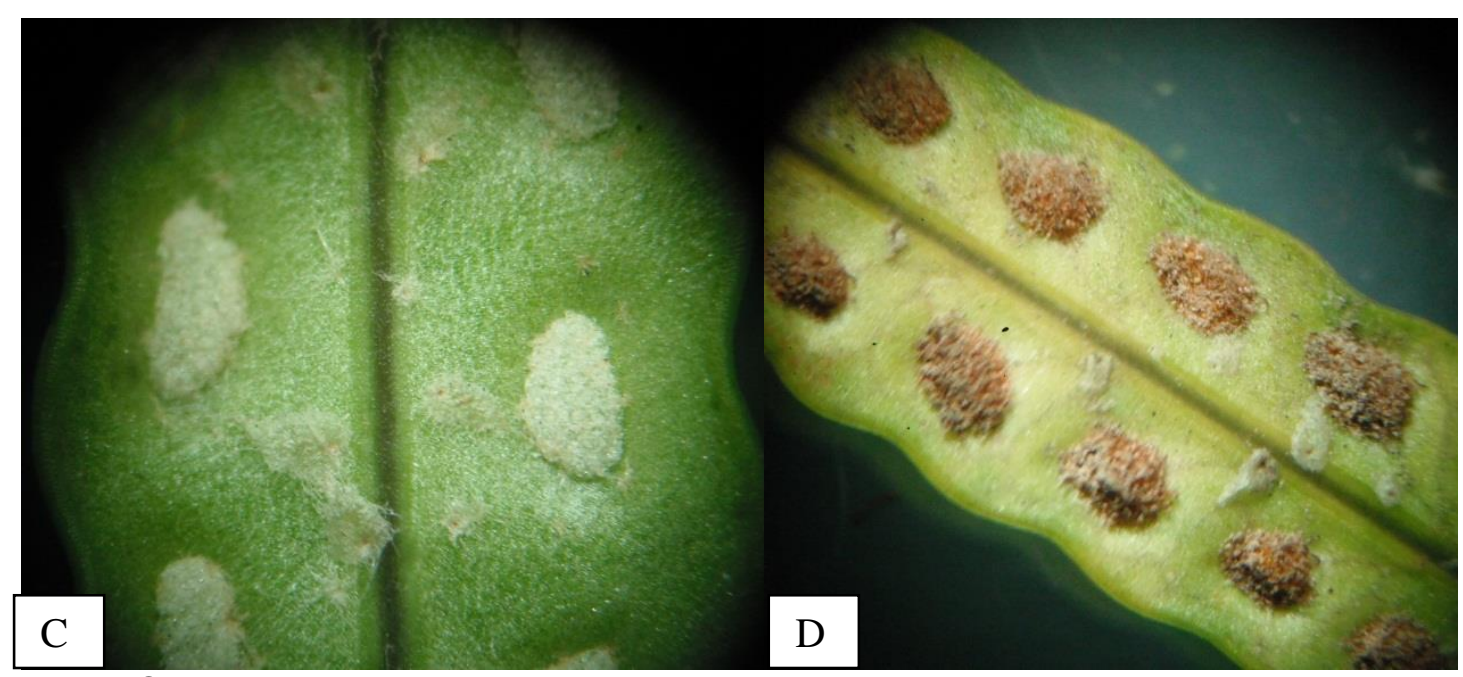

Fonte: Os autores.

FAMÍLIA CYATHEACEAE

GÊNERO CYATHEA

O gênero cyathea, denominado popularmente como xaxim (BUCKPU), é uma planta arborescente que apresenta um tufo de folhas na extremidade caulinar (SMITH, 1955), o que pode ser claramente observado no espécime encontrado na área de estudo (Figura 4). Os esporângios são grandes e numerosos, estão reunidos em soros arredondados, que estão protegidos por indúsio na forma de uma taça e que envolve o soro na base. As folhas são grandes, podendo atingir de 2 a 3 metros de comprimento. Os folíolos possuem nervuras que terminam nas margens dos mesmos (JOLY, 2002).

Figura 4: Gênero Cyathea, A) Tufo de folhas na extremidade caulinar; B) e C) Folíolo apresentando soros maturos; D) Soros maturos e abertos. 

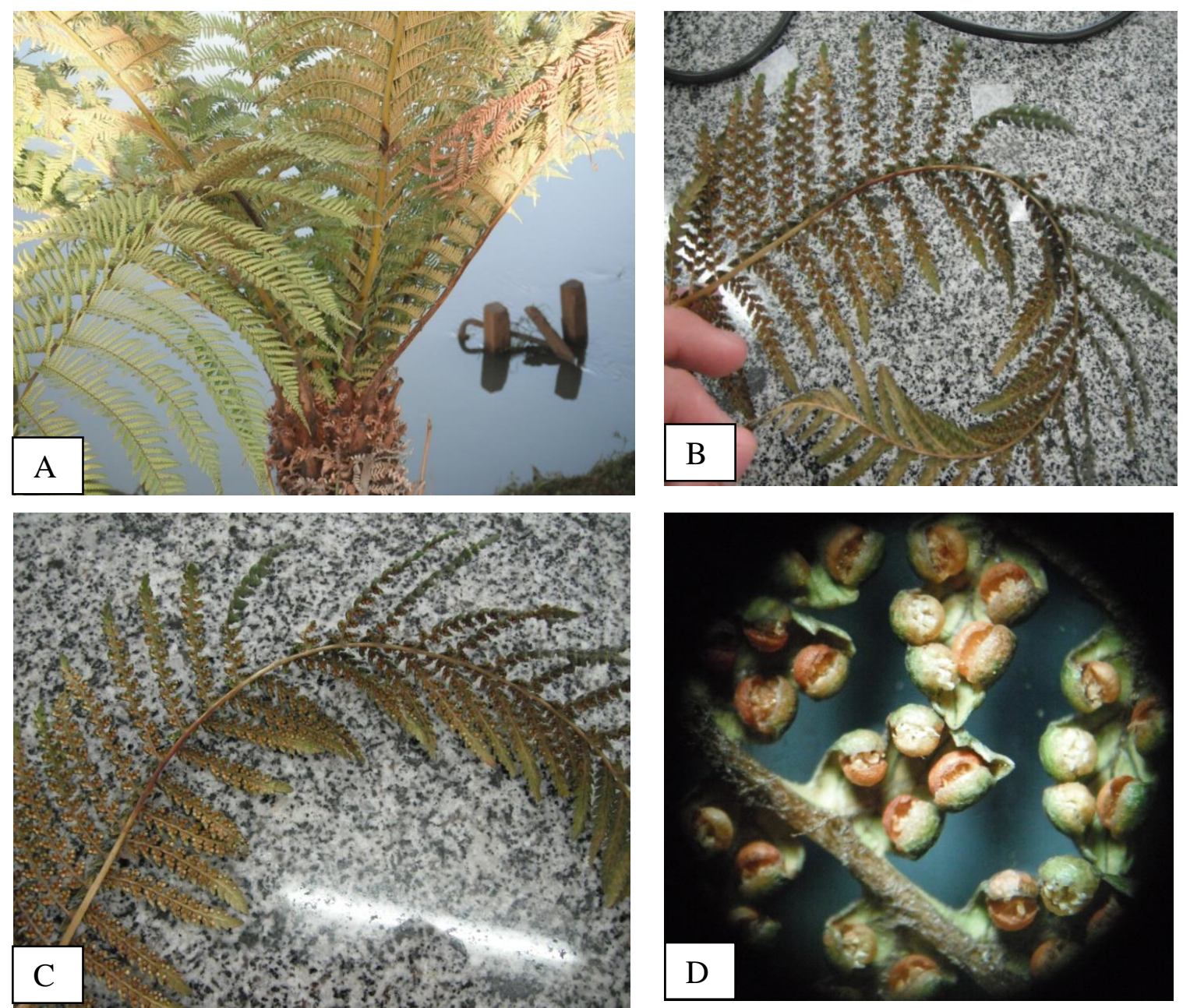

Fonte: Os autores.

FAMÍLIA SELAGINELLACEAE

GÊNERO SELAGINELLA

O gênero Selaginella reúne plantas herbáceas, terrestres, epífitas ou saxícolas, podendo habitar desde florestas úmidas até locais bastantes secos. (PIQUÉ e BRITO, 1996). As amostras coletadas foram encontradas debaixo se uma cobertura de gramíneas, a qual acabou impedindo que 
elas sobrevivessem em períodos mais úmidos, visto que o substrato ficou encharcado.

Em Selaginella o esporófito é herbáceo, ramificado dicotomicamente e está revestido por folhas que possuem lígula e que estão dispostas espiraladamente no ramo. As folhas podem ser todas iguais ou de dois tamanhos (heterofolia) (JOLY, 2002). As folhas encontradas na amostra eram todas do mesmo tamanho.

Figura 5: Gênero Selaginella. A) e C) Pontos secos por apodrecimento dos tecidos; B) coberto por gramíneas; D) Detalhe das folhas dispostas espiraladamente no ramo, sendo todas do mesmo tamanho.
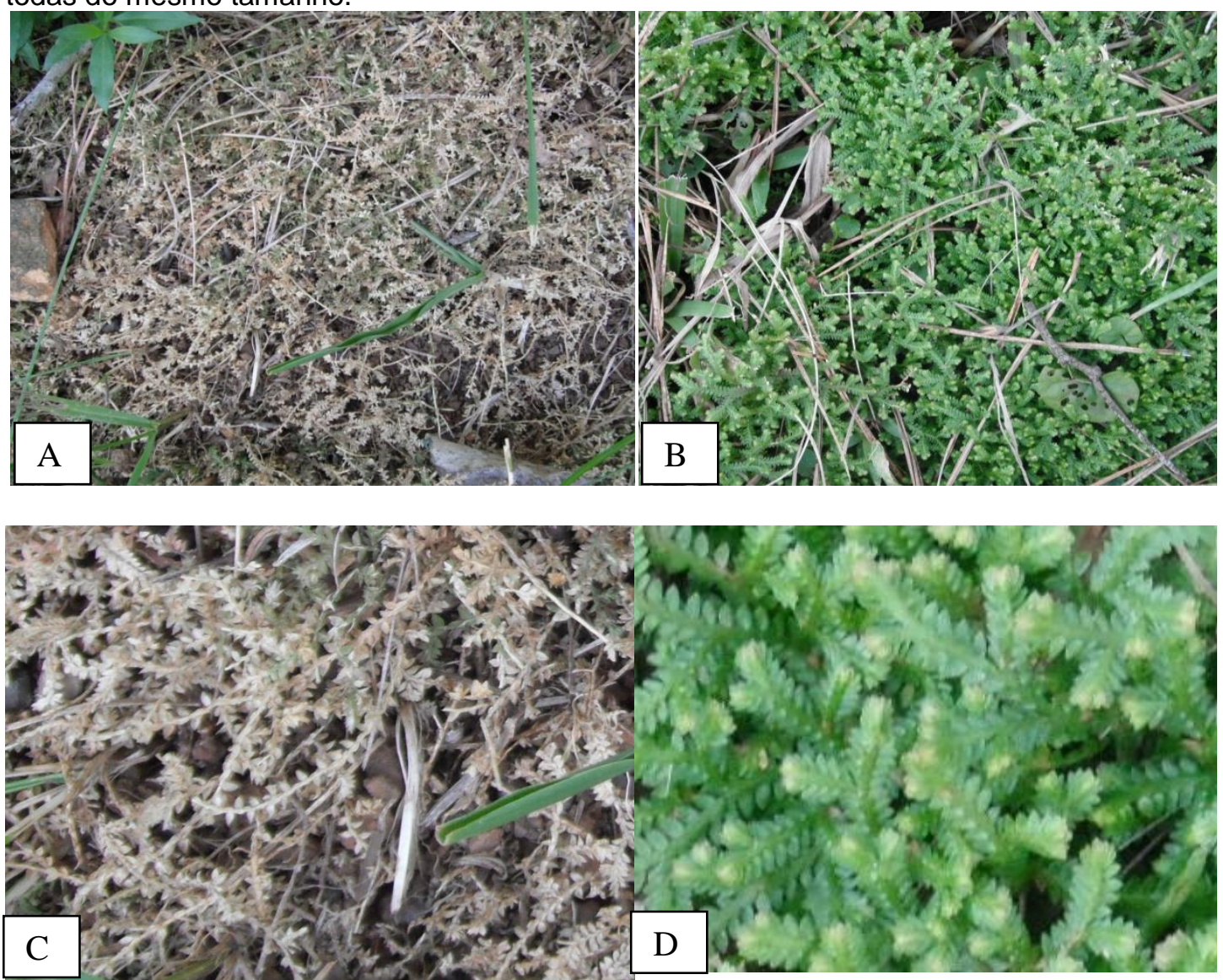

Fonte: Os autores. 
FAMÍLIA POLYPODIACEAE

\section{GÊNERO PTERIDIUM}

O gênero Pteridium é representado pelas samambaias, que ocupam um vasto território, habitando locais onde houve derrubada e queimada de mata (JOLY, 2002). É um dos pioneiros no processo de revestimento de um solo que teve sua vegetação destruída, visto que prefere habitar ambientes expostos ou áreas arborizadas com pouca sombra (SMITH, 1955)

As folhas, que podem chegar a tamanhos bastante grandes, estão inseridas de maneira alternada na face superior do rizoma (Figura 6), existindo entre elas longos entrenós. O limbo tem contorno triangular e é do mesmo comprimento do pecíolo (SMITH, 1955).

Figura 6: Gênero Pteridium. A) No seu habitat natural, às margens do Rio do Peixe em Caçador/SC; B) Detalhe dos folíolos; C) Crescimento das folhas paralelo ao solo e aderidos ao rizoma; D) Folhas inseridas de maneira alternada na face superior do rizoma.

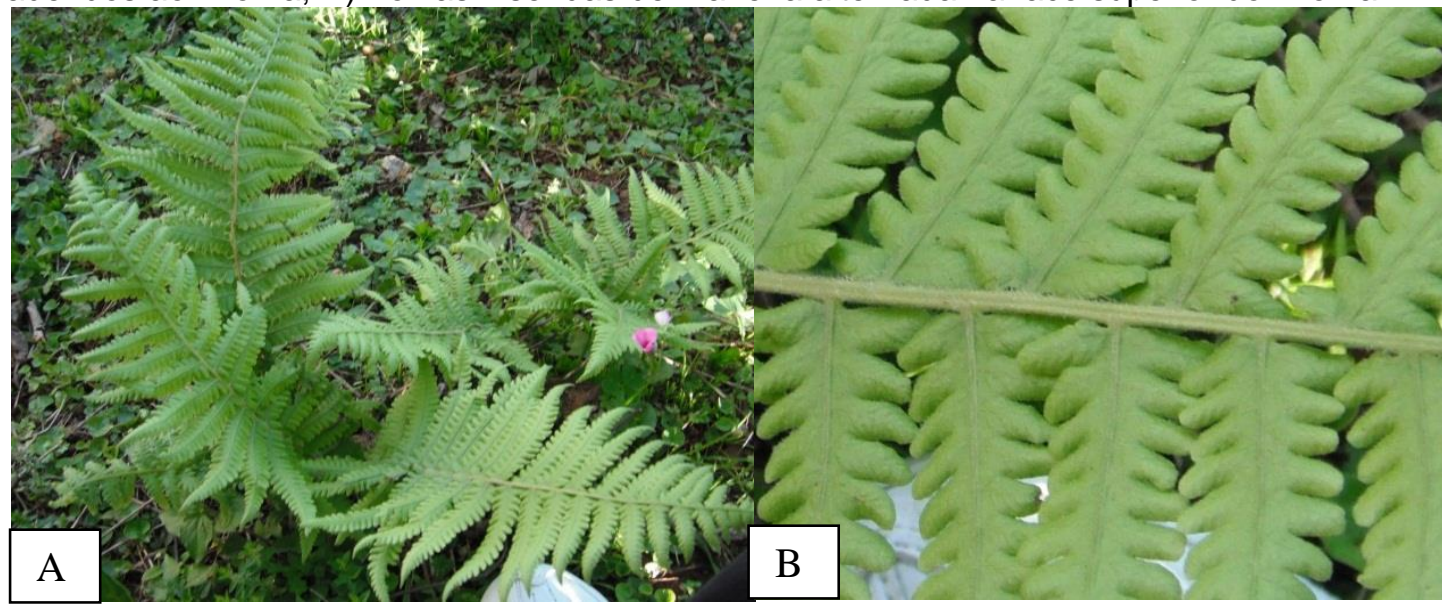



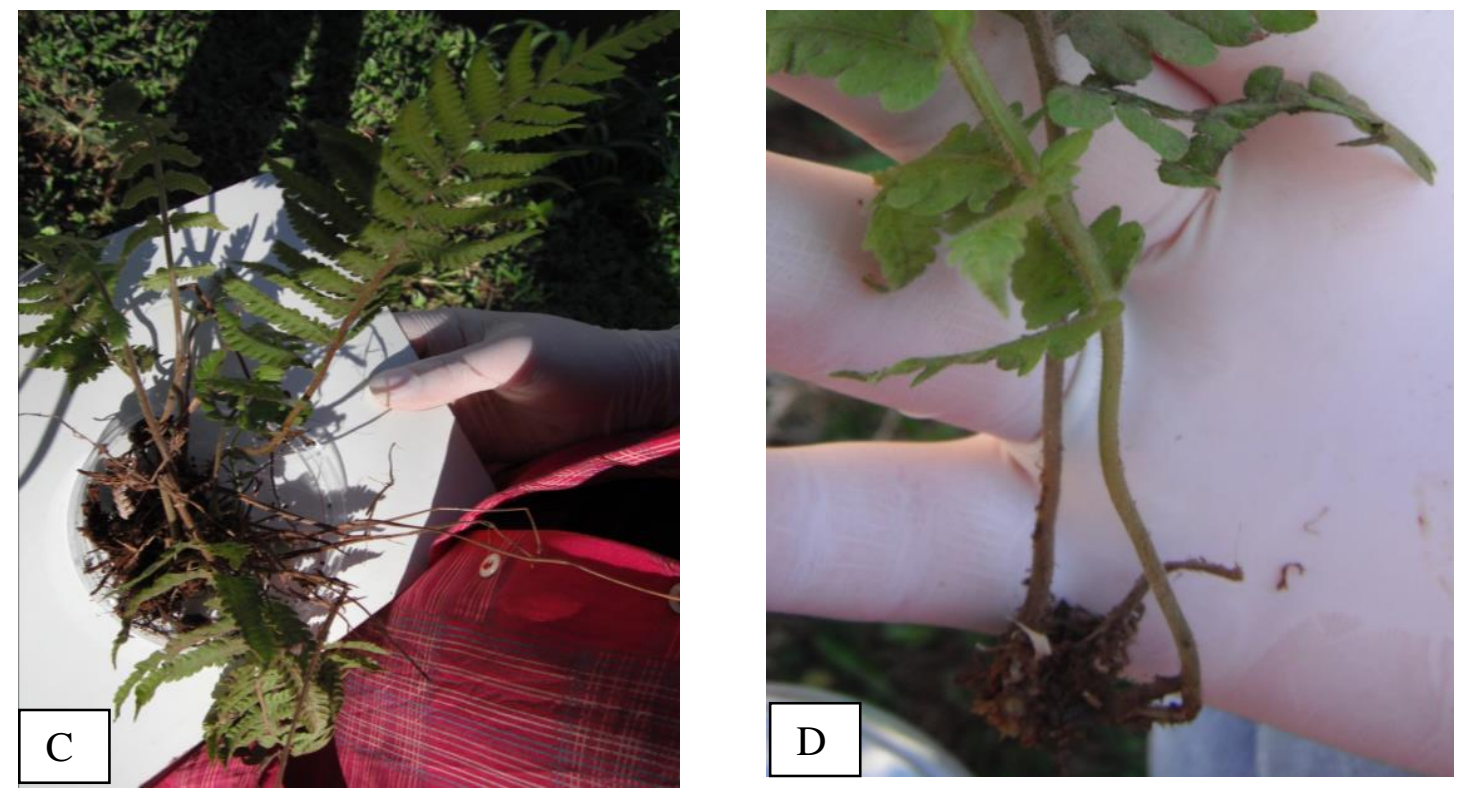

Algumas samambaias foram encontradas próximas ao muro que separa a calçada da região de coleta, estando infiltradas entre fendas e rochas. As raízes das fanerógamas penetram nas rochas, abrindo fendas, dando continuidade ao processo de desagregação muitas vez iniciado pelos liquens seguidos dos musgos (Raven;EVERT;CURTIS, 1978). Deste modo, as pteridófitas são responsáveis por dar continuidade ao processo de sucessão ecológica no tocante a plantas vasculares permitindo que ocorra o aparecimento da floresta e outros tipos de vegetação.

\section{CONCLUSÃO}

Foram encontradas seis espécies de vegetais de sucessão ecológica. Um gênero de Briófitas, o Polytrichum, pertencente à família Pilotrichacea.

Das pteridófitas, duas ordens, três famílias e cinco gêneros diferentes. Representantes da ordem Filicales foram os mais encontrados, se destacando duas famílias: Polypodiaceae, com três gêneros, 
Polypodium, Adiantum e Pteridium; e Cyatheaceae com apenas o gênero Cyathea. A ordem Selaginellales representada pela família Selaginellaceae e pelo gênero Selaginella.

Os registros fotográficos e bibliográficos serviram de base para elaboração do banco de dados sobre briófitas pteridófitas.

\section{AGRADECIMENTOS}

Agradecemos à Universidade Alto Vale do Rio do Peixe - UNIARP - pelas bolsas de estudo concedidas através do programa FAP - Fundo de Apoio à Pesquisa.

\section{REFERÊNCIAS}

BORDIN, Juçara e YANO, Olga. Briófitas do centro urbano de Caxias do Sul. Rio Grande do Sul, Hoehnea, v. 36, n. 1, p.7-71, 2009.

BUCKUP, Ludvig. Botânica. Porto Alegre: Sagra, [19--].

COSTA, Denise Pinheiro da; (Org.). Manual de Briologia. Rio de Janeiro: Interciência, 2010.

CHIARADIA, Adelheid M. L.. Minimanual de pesquisa - biologia. 2. ed. Uberlândia: Claranto, 2004.

JOLY, Aylthon Brandão. Botânica: introdução à taxonomia vegetal. 13. ed. São Paulo: Nacional, 2002.

PIQUÉ, Maria Pilar Roials; BRITO, Juarez Francisco. Atlas escolar de botânica. São Paulo: Ícone, 1996.

PRADO, Jefferson. Pteridófitas do estado de São Paulo. In: JOLY, C.A,; BICUDO, C.E.M (Org.). Biodiversidade do Estado de São Paulo, Brasil: Síntese do conhecimento ao final do século XX; 2: Fungos Macroscópicos e Plantas. São Paulo: FAPESP, 1998. p. 47-61.

PREFEITURA MUNICIPAL DE CAÇADOR. . Dados da cidade. Disponível 
em: <http://www.cacador.sc.gov.br/portalhome/index.php/cidade/87geografia>. Acesso em: 04 jun. 2012.

RAVEN, Peter H.; EVERT, Ray F.; EICHHORN, Susan E. Biologia vegetal. 6. ed. Rio de Janeiro: Guanabara Koogan, 2001.

SALVADOR, Domingues Elisabete. et al. Levantamento preliminar da pteridoflora da região de Guarapuava (PR). Ambiência, Guarapuava/PR, v.1, n. 2, p. 223-228, jun./dez. 2005.

SCHULTZ, Alarich R. Estudo prático da botânica geral. 4. ed. Porto Alegre: Globo, 1972.

SMITH, Gilbert M. Botânica criptogâmica - Briófitos e pteridófitos. 2. ed. Lisboa: Fundação Calouste Gulbenkian, 1955.

SOARES, José Luiz. Dicionário etimológico e circunstanciado de biologia. São Paulo: Scipione, 1993. 